\title{
Prognostic Value of Preoperative Echocardiographic Findings in Patients Undergoing Transvenous Lead Extraction
}

\author{
Dorota Nowosielecka $^{1}$, Wojciech Jacheć ${ }^{2}\left(\mathbb{D}\right.$, Anna Polewczyk ${ }^{3,4, * \mathbb{C}}$, Lukasz Tułecki ${ }^{5}$, Andrzej Kleinrok ${ }^{1,6}$ and $^{-}$ \\ Andrzej Kutarski ${ }^{7}$
}

check for

updates

Citation: Nowosielecka, D.; Jacheć, W.; Polewczyk, A.; Tułecki, Ł.;

Kleinrok, A.; Kutarski, A. Prognostic Value of Preoperative

Echocardiographic Findings in Patients Undergoing Transvenous Lead Extraction. Int. J. Environ. Res. Public Health 2021, 18, 1862. https:// doi.org/10.3390/ijerph18041862

Academic Editor: Michael R. Esco

Received: 30 December 2020

Accepted: 11 February 2021

Published: 14 February 2021

Publisher's Note: MDPI stays neutral with regard to jurisdictional claims in published maps and institutional affiliations.

Copyright: (c) 2021 by the authors. Licensee MDPI, Basel, Switzerland. This article is an open access article distributed under the terms and conditions of the Creative Commons Attribution (CC BY) license (https:/ / creativecommons.org/licenses/by/ $4.0 /)$.
1 Department of Cardiology, The Pope John Paul II Province Hospital, 22-400 Zamość, Poland; dornowos@wp.pl (D.N.); a.kleinrok@wp.pl (A.K.)

2 2nd Department of Cardiology, Silesian Medical University, 40-055 Zabrze, Poland; wjachec@interia.pl

3 Department of Physiology, Pathophysiology and Clinical Immunology, Collegium Medicum, Jan Kochanowski University, 25-369 Kielce, Poland

4 Department of Cardiac Surgery, Świętokrzyskie Cardiology Center, 25-001 Kielce, Poland

5 Department of Cardiac Surgery, The Pope John Paul II Province Hospital, 22-400 Zamość, Poland; luke27@poczta.onet.pl

6 Department of Physiotherapy, Medical College of University of Technology and Management, 35-225 Rzeszów, Poland

7 Department of Cardiology, Medical University, 20-059 Lublin, Poland; Andrzej.Kutarski@ptkardio.Lublin.pl

* Correspondence: annapolewczyk@wp.pl; Tel.: +48-6000-240-74

\begin{abstract}
Background: In patients referred for transvenous lead extraction (TLE) transesophageal echocardiography (TEE) often reveals abnormalities related to chronically indwelling endocardial leads. The purpose of this study was to determine whether the results of pre-operative TEE might influence the long-term prognosis. (2) Methods: We analyzed data from 936 TEE examinations performed at a high volume center in patients referred for TLE from 2015 to 2019. The follow-up was $566.2 \pm 224.5$ days. (3) Results: Multivariate analysis of TEE parameters showed that vegetations $(\mathrm{HR}=2.631$ [1.738-3.983]; $p<0.001)$ and tricuspid valve (TV) dysfunction unrelated to the endocardial lead $(\mathrm{HR}=1.481$ [1.261-1.740]; $p<0.001)$ were associated with increased risk for long-term mortality. Presence of fibrous tissue binding sites between the lead and the superior vena cava (SVC) and/or right atrium (RA) wall ( $\mathrm{HR}=0.285 ; p=0.035)$, presence of penetration or perforation of the lead through the cardiac wall up to the epicardium $(\mathrm{HR}=0.496 ; p=0.035)$ and presence of excessive lead loops $(\mathrm{HR}=0.528 ; p=0.026)$ showed a better prognosis. After adjustment the statistical model with recognized poor prognosis factors only vegetations were confirmed as a risk factor $(\mathrm{HR}=2.613$; $p=0.039$ ). A better prognosis was observed in patients with fibrous tissue binding sites between the lead and the superior vena cava (SVC) and/or right atrium (RA) wall (HR =0.270; $p=0.040)$. (4) Conclusions: Non-modifiable factors may have a negative influence on long-term survival after TLE. Various forms of connective tissue overgrowth and abnormal course of the leads modifiable by TLE can be a factor of better prognosis after TLE.
\end{abstract}

Keywords: transesophageal echocardiography; vegetations; tricuspid valve dysfunction; transvenous lead extraction; long-term survival

\section{Introduction}

Recently, due to the rising incidence of infectious and non-infectious complications related to cardiac implantable electronic devices (CIED), the number of transvenous lead extraction (TLE) procedures has also been increasing [1]. TLE is considered as a first-line strategy for the management of CIED-associated complications [2,3]. The rate of major complications associated with TLE has been estimated to range from 0.9 to $4.0 \%$, and most often there is damage to the heart or venous vessels; the lead extraction procedure carries a 0 to $0.4 \%$ risk of death $[2,3]$. Due to the continuous improvement in the extraction strategy, most patients with major complications are discharged from hospital in a good general 
state [4]. Therefore, theoretically the fate of patients after TLE should not differ from those who did not undergo TLE. There is a large volume of published studies describing TLE outcomes, however the results are still unsatisfactory, because mortality is $5-25 \%$ at one year, $8-38 \%$ at three years, $8-44 \%$ at 5 years and $10-60 \%$ at 10 years, with the lowest values encountered in patients with non-infectious indications and highest in those with lead-related infective endocarditis (LRIE) [5-23]. Previous studies have not analyzed the effect of echocardiographic phenomena on long-term survival of patients undergoing TLE, and few reports have only assessed their relationship with the risk of procedure. The main echocardiographic parameter considered in order to estimate the risk of surgery was the value of the left ventricular ejection fraction (LVEF) $[6,7,12,16]$ as well as the presence/size of vegetation $[7,9-11,13-15,18,19]$. Only a few studies based on small sample sizes considered a possible impact of asymptomatic masses on endocardial leads (AMEL) on the length of survival following TLE [24-29]. This paper provides an in-depth analysis of preoperative TEE findings and their usefulness for predicting long-term outcomes of TLE.

\section{Methods}

\subsection{Study Population}

A prospective analysis was carried out on data from preoperative TEE performed at a high-volume center during 936 TLE procedures from June, 2015 to October 2019. All patients gave their written informed consent to TLE and analysis of anonymized medical records, approved by the Bioethics Committee of the Regional Chamber of Physicians and Dentists in Lublin no. 288/2018/KB/VII.

\subsection{Factors Potentially Affecting Long-Term Survival after TLE}

In order to identify the factors that may influence long-term survival the following variables have been analyzed:

Patient-dependent factors: age (during TLE and at first CIED implantation), gender, NYHA class, LVEF, atrial fibrillation, chronic renal failure, diabetes, arterial hypertension, a history of coronary artery bypass graft (CABG), previous sternotomy, CHA2DS2-VAsc score, Charlson comorbidity index, chronic anticoagulation, and antiplatelet therapy.

CIED-related factors: the number of leads in the device before TLE, the number of leads the patient had before TLE, abandoned leads, excessive lead loops before TLE, high voltage (HV) leads, leads in the coronary sinus (CS), dwell time of the oldest lead in the patient, mean implant duration before TLE, cumulative dwell time of the extracted leads, and the number of CIED procedures before TEE.

Indication-related data: diagnosis of LRIE certain or probable with or without pocket infection or only local pocket infection.

TLE efficacy and complications: the rate of complete radiographic success, partial radiographic success, lack of radiographic success, clinical success, complete procedural success and presence of any major complication, hemopericardium, severe tricuspid valve damage during TLE, rescue cardiac surgery.

Most important preoperative TEE findings: tricuspid valve dysfunction, lead-dependent tricuspid valve dysfunction (LDTD), shadowing from the leads before TLE, fibrous tissue binding the lead to the heart structures, AMEL (fibrous tissue encasing the lead, lead thickening, clots and vegetation-like masses), vegetations, excessive lead loops and perforation or penetration of the lead through the cardiac wall up to the epicardium. 


\subsection{Lead Extraction Procedure}

TLE was defined according to EHRA consensus document as intervention with removal of at least one lead that has been implanted for more than one year or a lead regardless of duration of implant requiring the assistance of specialized equipment that is not included as part of the of the typical implant package and/or removal of a lead from a route other than the implant vein [30].

Complete procedural success was defined as removal of all targeted leads and material, with the absence of any permanently disabling complication or procedure-related death Clinical procedural success was defined as retention of a small portion of a lead $(<4 \mathrm{~cm})$ that does not negatively impact the outcome goals of the procedure and with absence of any permanently disabling complication or procedure-related death [30].

Extraction procedures were performed in a hybrid operating room or in an operating room, using mechanical systems such as polypropylene Byrd dilators (Cook ${ }^{\circledR}$ Medical, Leechburg, PA, USA), making use of the oblique cutting edge of the tip to dissect leads from fibrous sheaths that immobilized the lead in the intravascular and/or intracardiac segment $[11,28]$. Procedures were performed in patients under general anesthesia and after preparation of the surgical field as for subjects coming in for cardiac surgery. Continuous invasive blood pressure monitoring from radial artery was used. The composition of the surgical team and the course of the extraction procedure have been described in detail elsewhere [31-33].

\subsection{Preoperative TEE}

TEE was performed using the Philips iE33 (Phillips Healthcare, Andover, MA, USA) or the GE Vivid S70 (General Electric Company, Boston, MA, USA) ultrasound machine equipped with X7-2t Live 3D or 6VT-D probes. Images and recordings were obtained before the procedure, after general anesthesia and tracheal intubation, during preparation of the surgical field, and dissection and stabilization of the leads in the region of the device pocket. Leads were evaluated in the mid-esophageal, inferior esophageal and modified transgastric views to visualize the right heart chambers and the tricuspid valve. In order to obtain complete visualization of the structures (and assessment of lead/heart interface) non-standard imaging planes were sometimes required. After the procedure the results were entered into a computer database. The TEE examination was described in detail in previous publications- we followed the methods of Nowosielecka et al. [31-33].

\subsection{Echocardiographic Findings Associated with Endocardial Leads: Definition and Classification According to the Anatomy and Characteristic Features}

Asymptomatic masses on endocardial leads (AMEL) [31]: Additional masses on the leads classified as clots (varying degrees of organization), components of connective tissue (so-called accretions), masses resembling vegetations (vegetation-like masses), probably the remnants after infections: Old fibrous vegetations or clots (Figure 1).

Bacterial vegetations [31], i.e., multishaped, mobile masses of inhomogeneous echogenicity. Vegetations were diagnosed only if they were accompanied by signs of a general infection (positive inflammatory markers, positive blood cultures) or a regional infection (pocket infection) (Figure 2). 


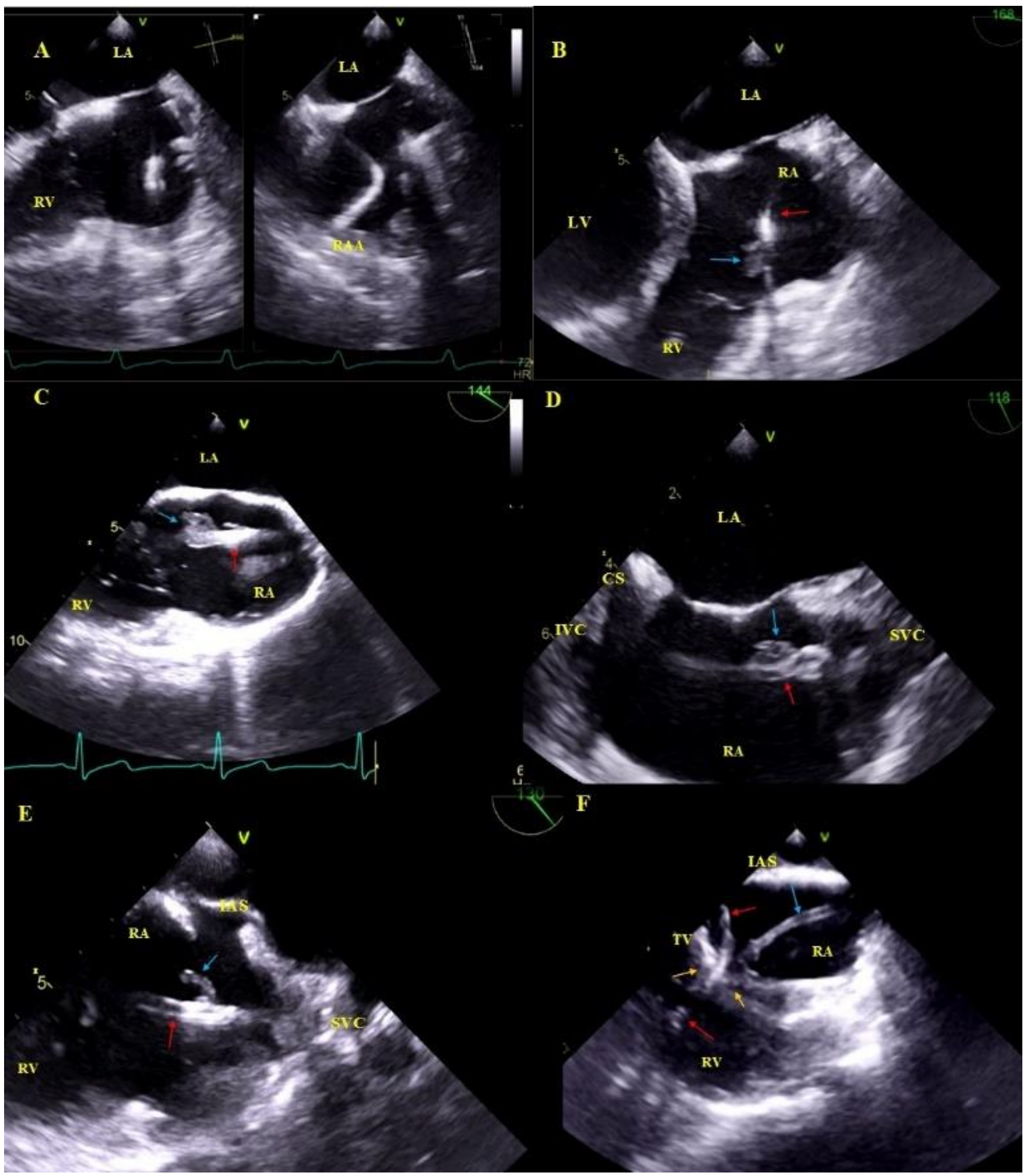

Figure 1. Asymptomatic masses on endocardial leads in 2D TEE. (A) - Thickened hyperechoic distal segment of atrial lead surrounded by a connective tissue sheath. (B) - Thickened hyperechoic segment of atrial lead (red arrow) with a mobile mass representing a clot (blue arrow). (C,D) - Ventricular lead (red arrow) in the RA with mobile vegetation-like masses (blue arrow) (2D, ME modified and bicaval). (E) - Ventricular lead (red arrow) in the RA with a mobile connective tissue mass (accretion) (blue arrow). (F)-The thickened ventricular lead adhered to the TV leaflets, in addition, in RA, the echo associated with the TV (blue arrow) is the sheath of silicone insulation remaining after the first TLE of removing the previous ventricular lead. The place of growth is marked with yellow arrows. 


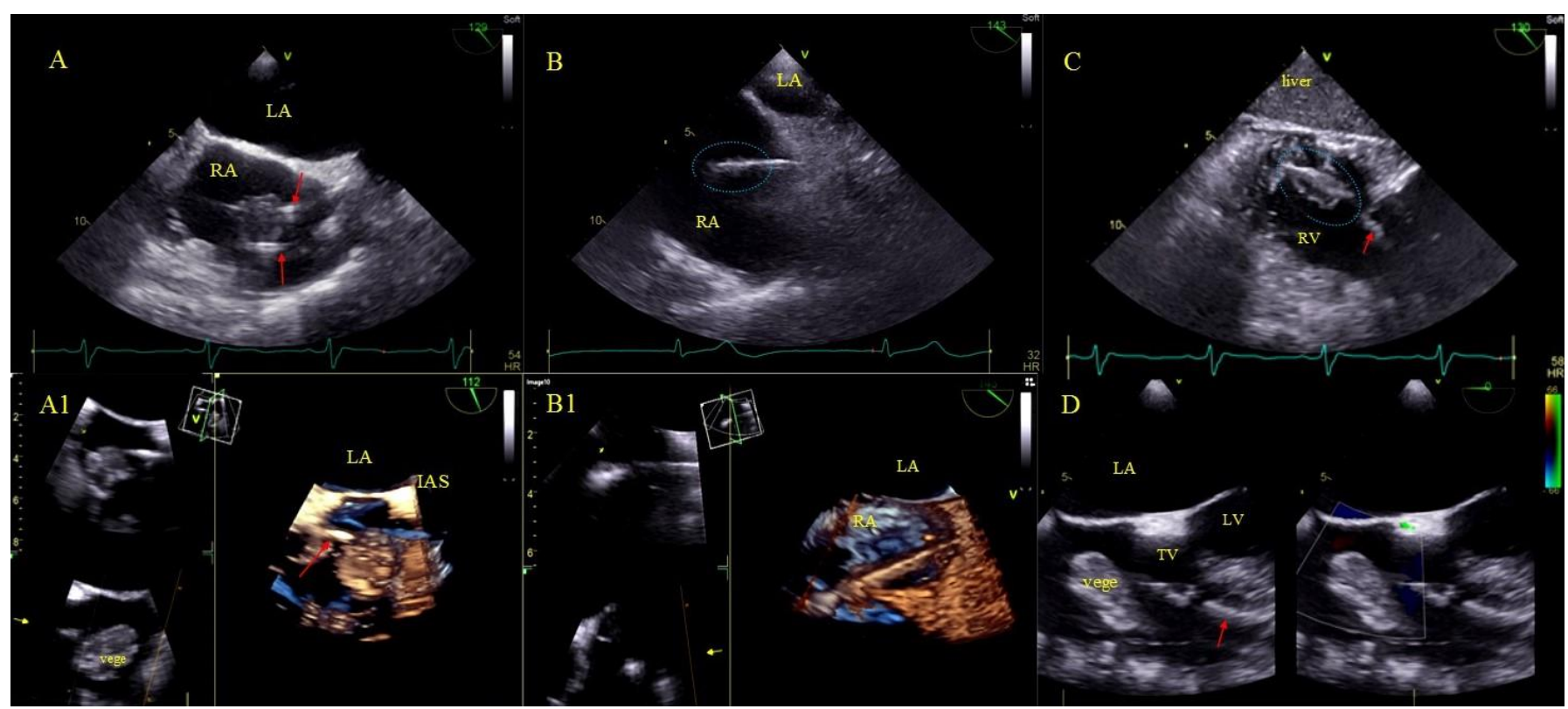

Figure 2. LRIE—TEE images of bacterial vegetations attached to CIED leads. (A,A1)-Bacterial vegetation attached to the lead (red arrows) in the RA in 2D and 3D TEE (bicaval). (B,B1)-Fine vegetations on the lead causing lead thickening with irregular contour (blue circle) in 2D TEE (B)—well visible in 3D TEE (B1)—(bicaval). (C)—Echoes of the lead (red arrow) with vegetations (blue circle) in the RV (2D, TG, TEE). (D)-Large bacterial vegetation attached the ventricular lead (red arrow) dislodging to the TV orifice without significant impact on valve function. The size of the vegetation disqualifies the patient from TLE (2D, 4-CH TEE).

Hyperechoic segmental thickening of the leads defined as connective tissue overgrowth (undergoing fibrosis, mineralization, crystallization and even ossification) [31].

Buildup: Fibrous connective tissue sheath around the lead causing adherence to the endocardium and vessel walls producing images similar to segmental lead thickening but moving along with the cardiac wall. The term encompasses also segmental lead-to-lead adhesion (two or three leads) moving along together with the cardiac walls. Immobile masses binding the lead to the vein or heart wall most frequently represent a sign of preexisting asymptomatic inflammatory response triggered by the endocardial lead (foreign body reaction). Over time, fibrosis ensues with the presence of calcifications (mineralization, crystallization and ossification). This type of reaction may occur in patients with and without device infections [31] (Figure 3). 


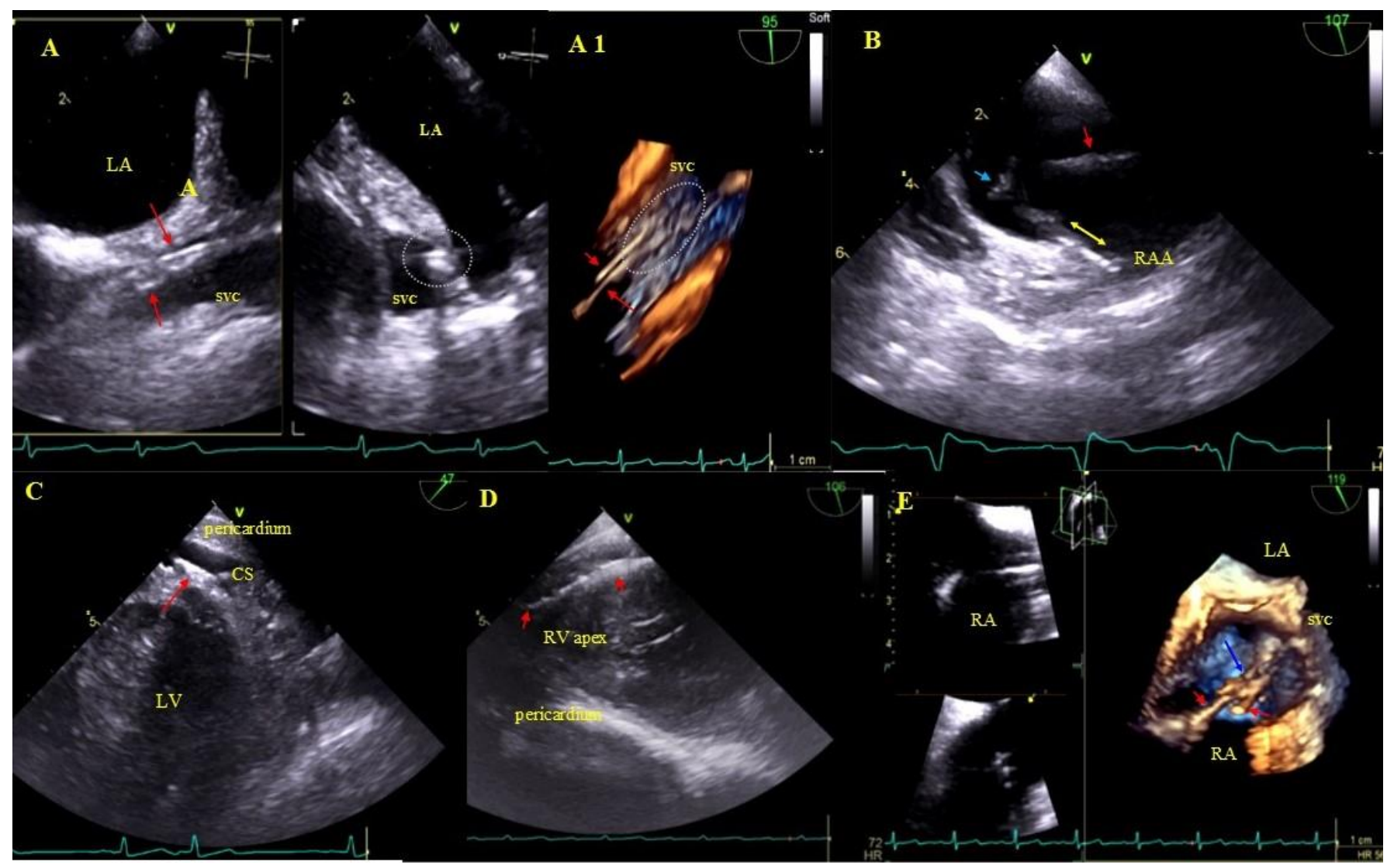

Figure 3. Lead adhesion in various parts of the cardiovascular system. (A,A1) - Two leads (red arrows) bound together and adhering to the SVC wall (2D and 3D, bicaval). (B) - The end of the atrial lead (red arrow) implanted in the RAA adhering to the RA wall (yellow arrow) and a mass on the lead (accretion) (blue arrow) (2D, bicaval, modified). (C) - In the coronary sinus the end of the lead adhering to the vascular wall (red arrow) (2D, TG modified). (D) - Long distal end of the ventricular lead (red arrows) adhering to the RV endocardium (2D, TG). (E) - In the RA an additional leads (red arrows) fibrous mass (accretion) (blue arrow) at the binding site (3D, bicaval).

Other, separately classified lead-associated phenomena: Lead-dependent tricuspid dysfunction: valve regurgitation (very rarely TV stenosis) unquestionably caused by the lead (lead impingement, lead entanglement with tendinous chords, lead adhesion to the leaflet, leaflet perforation) [31] (Figure 4). 


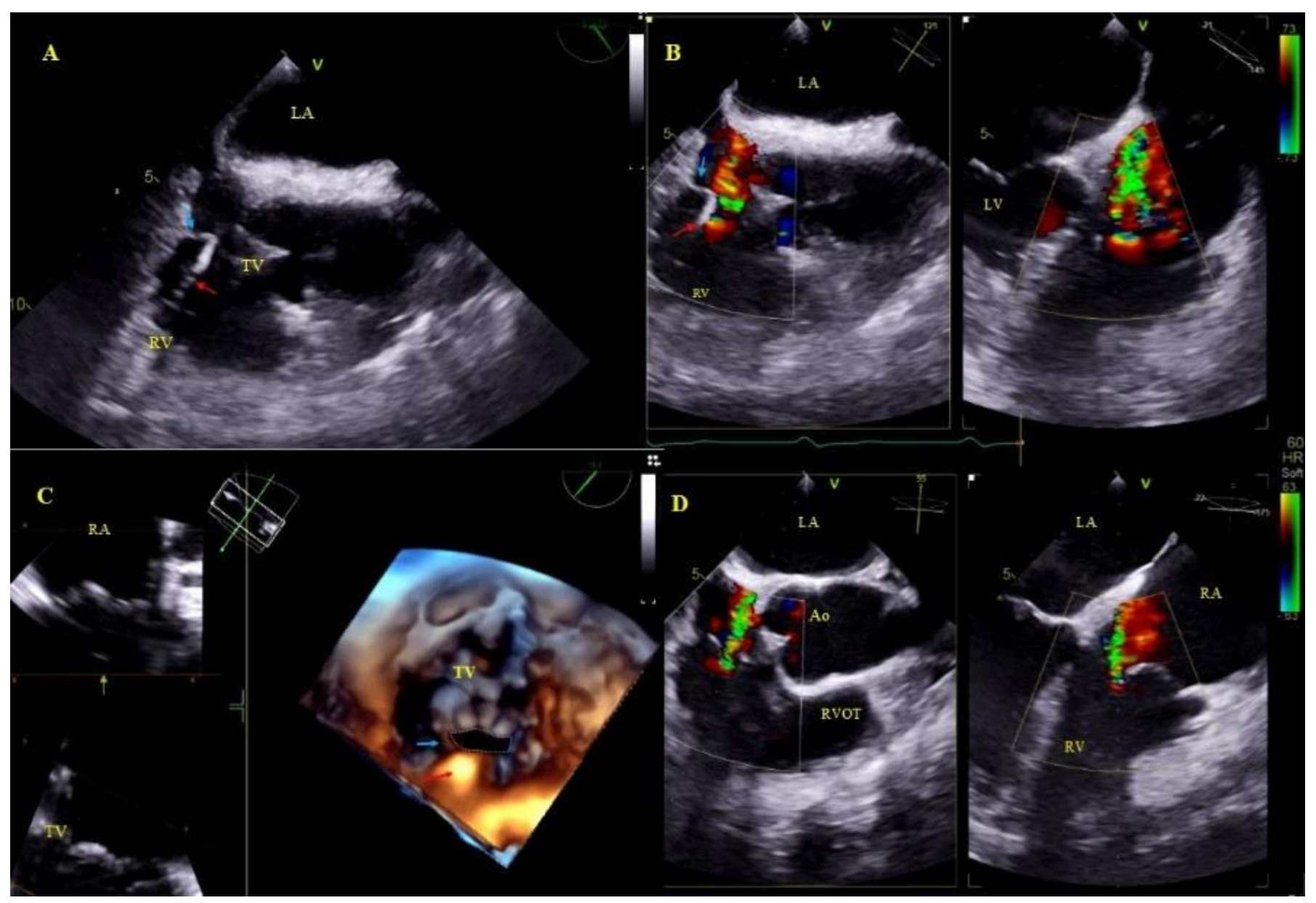

Figure 4. Lead-dependent tricuspid dysfunction (LDTD) due to lead impingement (A) - The lead (red arrow) impinging on the posterior TV leaflet (blue arrow) (2D, ME). (B) - Color Doppler shows severe tricuspid regurgitation before TLE (red arrow-lead, blue arrow- posterior TV leaflet). (C)-3D TEE viewed from the RV-impinging on the posterior TV leaflet (red arrow-lead, blue arrow- posterior TV leaflet). (D)-Moderate tricuspid regurgitation after the extraction procedure (2D, color Doppler).

Cardiac wall perforation by the lead: visualization of the lead tip outside the heart contour, frequently with fluid in the pericardial sac; placement of the lead tip close to the border of the pericardium is referred to as penetration (Figure 5). 


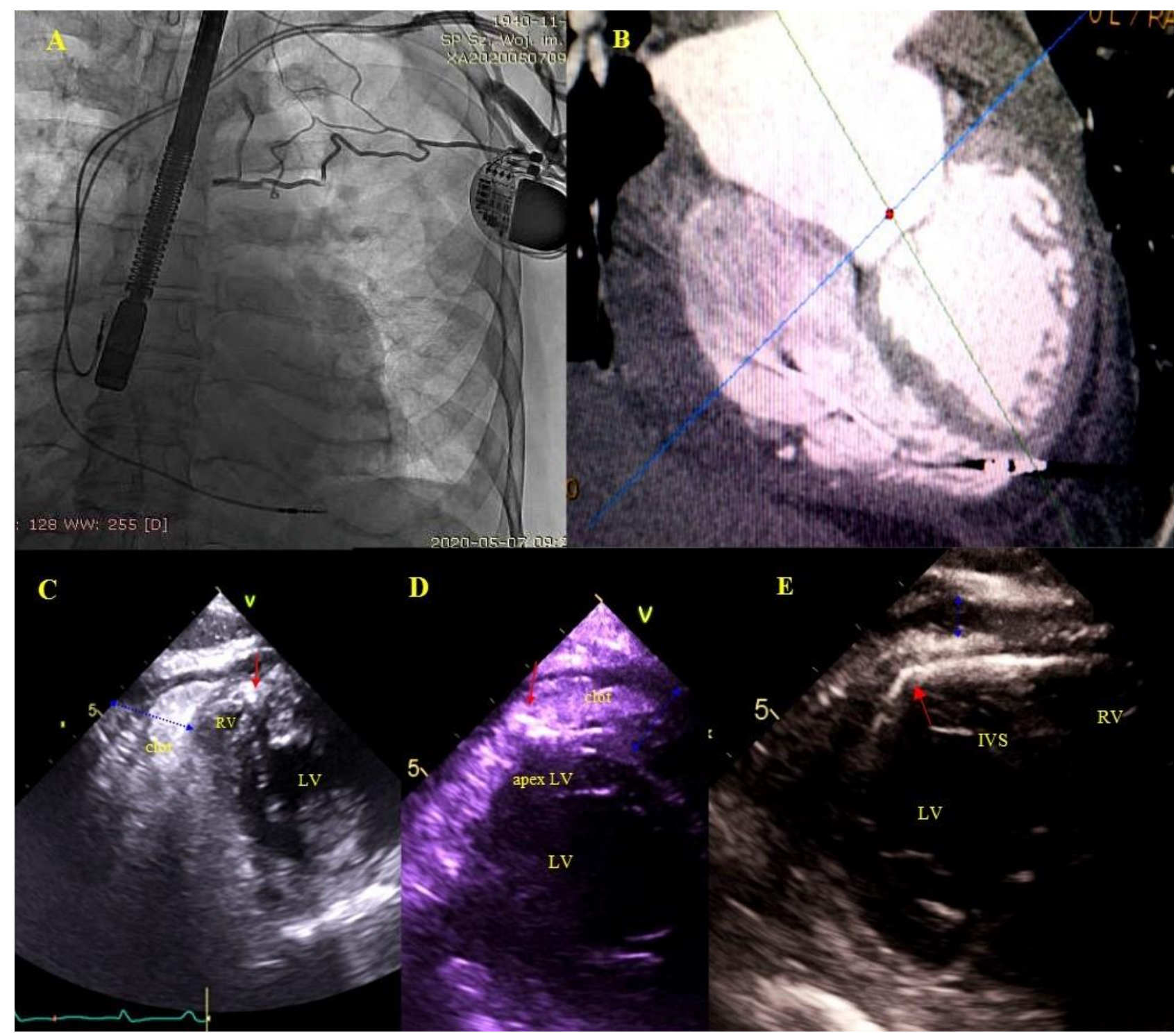

Figure 5. Right ventricular wall perforation by the ventricular lead. An 80-year-old patient with a DDD pacemaker and recurrent pericardial effusion for 3 months. Based on the location of the ventricular lead tip on chest X rays (A) - and TEE, perforation of the RV wall was suspected. ECG-gated CT confirmed the diagnosis (B) - TEE (2D, TG) during the procedure visualized the end of the perforating lead (red arrows) (C-E) - and a clot in the pericardium (blue arrow) (C,D).

Excessive lead loops as a result of too weak fixation during implantation or lead fracture with insulation breach in the subclavian region. Excessive lead loops may be encountered in the right atrium or the right ventricle, and in the tricuspid valve orifice (Figure 6). 


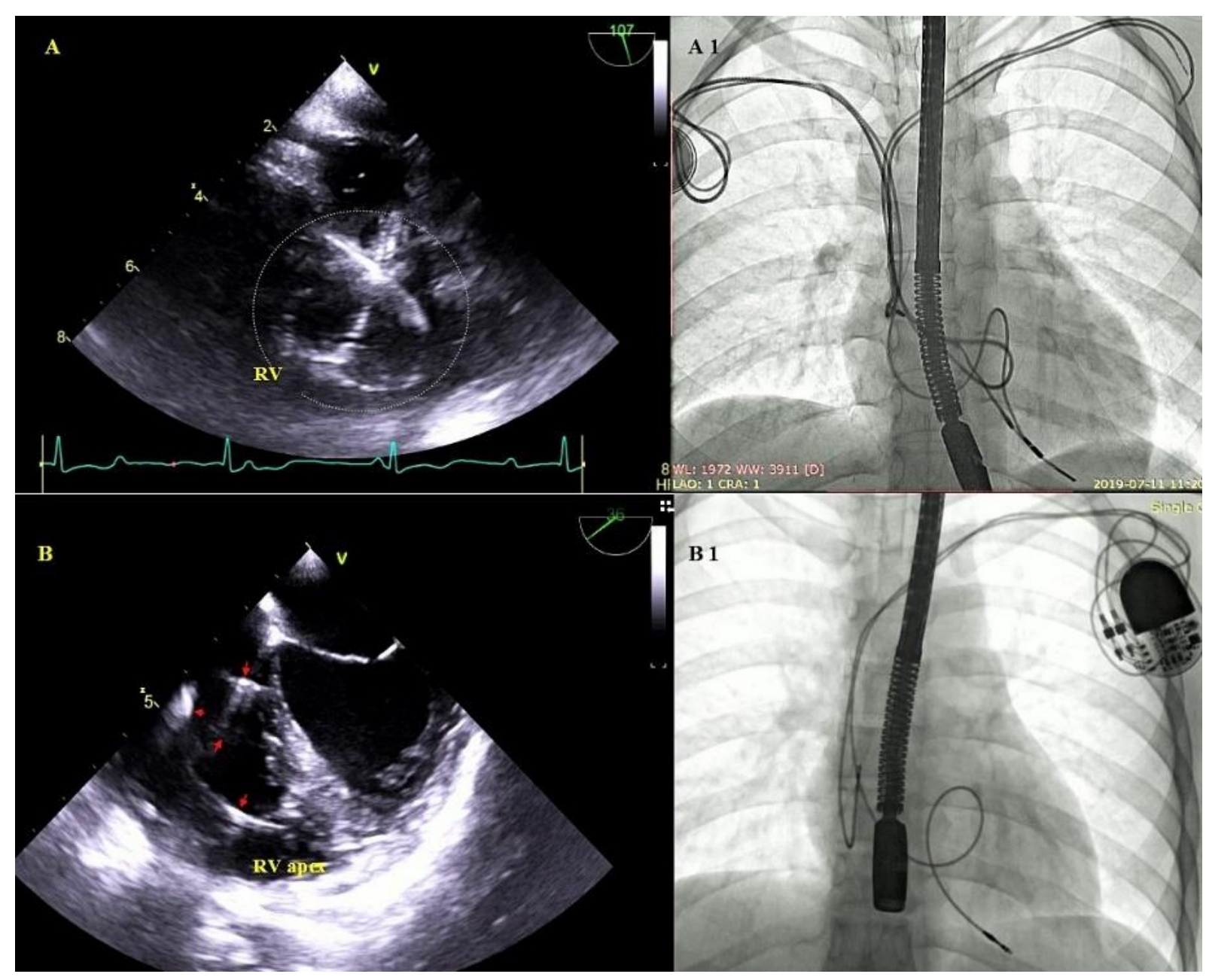

Figure 6. Excessive lead loops in TEE and fluoroscopy during TLE. (A,A1)—Excessive loops of ventricular and atrial leads (white circle) visualized in the RV cavity with multifocal lead-to-lead binding. (B,B1)_Excessive loop of the ventricular lead (red arrows) in the RV cavity.

\section{Statistical Analysis}

The Shapiro-Wilk test was used to test the distribution of continuous variables. A nonparametric distribution of all continuous variables was found. For a clearer presentation of the results, all continuous variables are presented as the mean \pm standard deviation and some of them (patient age during TLE and during first CIED implantation, left ventricle ejection fraction, dwell time of the oldest lead in the patient) additionally as median with the first and the third quartile. The categorical variables are presented as number and percentage. The study population was divided into two groups depending on TLE outcomes (survival versus death) at two-year follow-up. The significance of differences between the groups was determined using the nonparametric "U" Mann-Whitney test and Chi square tests. The relationship between the echocardiographic parameters and mortality after TLE was analyzed using Cox regression analysis. All variables reached $p<0.1$ in univariate analysis were included into a multivariate model. Two multivariate regression models were defined. Model 1 was built to assess the prognostic value of the echocardiographic variables only. Model 2 included echocardiographic variables from model 1 and adjusted by clinical parameters of known prognostic values (patient age at first implantation, patient age during TLE, gender, LVEF, NYHA functional class, presence of diabetes mellitus, renal failure, arterial hypertension, infectious indications for TLE, ICD and CRTD prior to TLE). Moreover, the impact of the binding sites between leads and VCS wall and/or right atrial wall and survival after TLE was presented as the Kaplan-Meier 
survival curves. The log rank test was used to compare the survival distributions of the groups. A two-tailed $p$ value $<0.05$ was considered statistically significant.

Statistical analysis was performed with STATISTICA 13.0 (TIBCO Software Inc. Krakow, Poland). All patients gave informed consent for TLE and anonymous analysis of their medical records, approved by the local Bioethics Committee.

\section{Results}

Transesophageal echocardiography before TLE was performed in 936 patients ( 355 women; $37.93 \%$ ), with a mean age of $67.08 \pm 14.50$ years. The indications for TLE were mainly noninfectious (727 patients; $77.67 \%$ ). Pocket infection was recognized in 58 $(6.20 \%)$ patients, whereas lead-related infective endocarditis in 151 (16.13\%) individuals. The follow-up after TLE was $566.2 \pm 224.5$ days (range: $2-730$ ). There were 112 deaths during follow-up. Patients with infectious indications for TLE, especially with LRIE, had a worse survival compared to patients with non-infectious indications: $559.4 \pm 266.8$ vs. $670.6 \pm 167.8$ days; $p<0.001$ (the time of survival during follow-up were calculated for patients with completed two-years follow-up, $n=612$ ).

\subsection{Prognostic Factors}

\subsubsection{Prognostic Factors Not Related to TEE Findings and TLE Procedure}

Most of these deaths were attributed to patient-dependent risk factors: older age at first CIED implantation $(p<0.001)$, older age during TLE $(p<0.001)$, male gender $(p=0.003)$, higher NYHA class $(p<0.001)$, low $\operatorname{LVEF}(p<0.001)$, atrial fibrillation $(p<0.001)$, chronic renal failure (increased, creatinine concentration $>1.3 \mathrm{mg} / \mathrm{dl})(p<0.001)$, higher CHA2DS2-VAsc score (increased, $p<0.001)$, higher Charlson comorbidity index $(p<0.001)$ and chronic anticoagulation therapy $(p<0.001)$ (Table 1$)$.

\subsubsection{Prognostic Factors Related to Implanted Devices}

Of CIED-related factors, HV therapy (ICD lead presence) $(p=0.016)$, leads in the CS (LV pacing) $(p<0.001)$ and a higher number of leads the patient had before TLE $(p=0.029)$ were associated with lower survival rates. Similarly, infectious indications for TLE (LRIE) were associated with worse long-term survival $(p<0.001)$ (Table 1$)$.

\subsubsection{Prognostic Factors Related to TLE Procedure}

The factors related to procedure efficacy and major complications did not affect significantly long-term outcomes after TLE (Table 1).

\subsubsection{Prognostic Factors Related to TEE Findings}

Of preoperative TEE variables, tricuspid valve dysfunction (degree of regurgitation) $(p<0.001)$ and vegetations $(p<0.001)$ were significantly more common among those who died after TLE. In contrast, the signs of connective tissue overgrowth occurred significantly more often among those who survived: fibrous tissue binding the lead to the superior vena cava and heart structures $(p=0.024)$, fibrous tissue binding the lead to the heart structures (all) $(p=0.008)$, fibrous tissue binding the lead to the RA wall $(p<0.001)$, lead-to-lead adhesion $(p<0.009)$, asymptomatic masses on endocardial leads (all) $(p=0.022)$, and fibrous tissue encasing the lead $(p=0.021)$. Similarly, the presence of (any) lead loops in the heart before TLE $(p=0.037)$ and perforation or penetration of the lead through the cardiac wall up to the epicardium ( $p=0.038)$ were associated with better chances of long-term survival (Table 2). 
Table 1. Preliminary analysis of all parameters as potential risk factors for early death after TLE.

\begin{tabular}{|c|c|c|c|c|}
\hline & All Group $n=936$ & Alive $n=824$ & Death $n=112$ & $\begin{array}{c}\text { “U” Mann- } \\
\text { Whitney/ } \\
\text { X }^{2} \text { Test }\end{array}$ \\
\hline $\begin{array}{l}\text { Follow-up (days); mean } \pm \mathrm{SD} ; \text { (min.-max.); } \\
\text { median, }\left[\mathrm{Q}_{1} ; \mathrm{Q}_{3}\right]\end{array}$ & $\begin{array}{l}566.2 \pm 224.5(2-730) \\
730.0[397.0 ; 730.0]\end{array}$ & $\begin{array}{l}604.4 \pm 196.0(64-730) \\
730.0[505.0 ; 730.0]\end{array}$ & $\begin{array}{l}285.3 \pm 221.6(2-725) \\
242.0[75.0 ; 450.5]\end{array}$ & $p<0.001$ \\
\hline \multicolumn{5}{|c|}{ Demographic and clinical data } \\
\hline $\begin{array}{l}\text { Patient age during TLE (years); mean } \pm \text { SD; } \\
\text { median, }\left[\mathrm{Q}_{1} ; \mathrm{O}_{3}\right]\end{array}$ & $\begin{array}{c}67.08 \pm 14.50 \\
69.20[61.10 ; 77.80]\end{array}$ & $\begin{array}{c}66.07 \pm 4.79 \\
69.40[60.60 ; 77.40]\end{array}$ & $\begin{array}{c}73.29 \pm 10.54 \\
73.30[66.70-82.20]\end{array}$ & $p<0.001$ \\
\hline $\begin{array}{l}\text { Patient age at first CIED implantation (years); mean } \pm \text { SD; } \\
\text { median, }\left[\mathrm{Q}_{1} ; \mathrm{Q}_{3}\right]\end{array}$ & $\begin{array}{l}57.28 \pm 16.09 \\
60.40[50.20 ; 68.10]\end{array}$ & $\begin{array}{l}56.32 \pm 16.45 \\
60.80[49.90 ; 68.20]\end{array}$ & $\begin{array}{c}64.38 \pm 10.85 \\
65.30[59.10 ; 72.80]\end{array}$ & $p<0.001$ \\
\hline Sex (female); $n(\%)$ & $355(37.927)$ & $327(39.684)$ & $28(25.000)$ & $p=0.004$ \\
\hline NYHA class; (mean \pm SD) & $2.029 \pm 0.574$ & $1.985 \pm 0.560$ & $2.348 \pm 0.581$ & $p<0.001$ \\
\hline $\operatorname{LVEF}(\%) ;($ mean $\pm \mathrm{SD})$ & $\begin{array}{c}47.89 \pm 15.56 \\
53.00[34.50 \cdot 60.20]\end{array}$ & $\begin{array}{c}48.97 \pm 15.05 \\
55.40[35.00 \cdot 60.10]\end{array}$ & $\begin{array}{c}39.94 \pm 16.96 \\
37.00[25.70 \cdot 55.30]\end{array}$ & $p<0.001$ \\
\hline Atrial Fibrillation; $n(\%)$ & $\begin{array}{l}53.00[34.50 ; 60.20] \\
219(23.397)\end{array}$ & $\begin{array}{l}55,40[35.00 ; 60.10] \\
177(21.279)\end{array}$ & $\begin{array}{c}37.00[25.70 ; 55.30] \\
42(37.500)\end{array}$ & $p<0.001$ \\
\hline Chronic kidney disease (creatinine concentration $>1.3 \mathrm{mg} / \mathrm{dL}$ ); $n(\%)$ & $230(24.892)$ & $173(21.297)$ & $57(51.351)$ & $p<0.001$ \\
\hline Diabetes (any); $n(\%)$ & $198(21.154)$ & $167(20.267)$ & $31(27.679)$ & $p=0.093$ \\
\hline CABG history; $n(\%)$ & $74(7.906)$ & $65(7.888)$ & $9(8.036)$ & $p=0.895$ \\
\hline Previous sternotomy; $n(\%)$ & $132(14.103)$ & $116(14.078)$ & $1614.286)$ & $p=0.932$ \\
\hline Arterial hypertension; n (\%) & $482(51.496)$ & $433(52.549)$ & $49(43.750)$ & $p=0.100$ \\
\hline $\mathrm{CHA} 2 \mathrm{DS} 2-\mathrm{VAsc} ;$ mean $\pm \mathrm{SD}$ & $3.005 \pm 1.487$ & $2.914 \pm 1.763$ & $3.682 \pm 1.502$ & $p<0.001$ \\
\hline Charlson comorbidity index; mean $\pm \mathrm{SD}$ & $4.886 \pm 3.764$ & $4.674 \pm 3.751$ & $6.555 \pm 3.557$ & $p<0.001$ \\
\hline Need for long-term anticoagulation; $n(\%)$ & $389(41.560)$ & $323(39.199)$ & $66(58.929)$ & $p<0.001$ \\
\hline Need for long-term antiplatelet therapy; $n(\%)$ & $424(45.299)$ & $365(44.296)$ & $59(52.679)$ & $p=0.116$ \\
\hline \multicolumn{5}{|c|}{ CIED-related data } \\
\hline Number of leads in the system before TLE; mean \pm SD & $1.834 \pm 0.639$ & $1.817 \pm 0.611$ & $1.946 \pm 0.745$ & $p=0.122$ \\
\hline Presence of abandoned lead before TLE; $n(\%)$ & $86(9.188)$ & $74(8.981)$ & $11(9.821)$ & $p=0.908$ \\
\hline Presence of HV therapy (ICD) lead; $n(\%)$ & $296(31.624)$ & $249(30.218)$ & $47(41.964)$ & $p=0.016$ \\
\hline Presence of CS (LV pacing) lead; $n(\%)$ & $153(16.346)$ & $120(14.563)$ & $33(29.464)$ & $p<0.001$ \\
\hline Number of leads in the patient before TLE; mean \pm SD & $1.954 \pm 0.729$ & $1.934 \pm 0.718$ & $2.098 \pm 0.718$ & $p=0.040$ \\
\hline $\begin{array}{l}\text { Dwell time of the oldest lead in the patient (months); mean } \pm \mathrm{SD} \text {; } \\
\text { median, }\left[\mathrm{Q}_{1}: \mathrm{Q}_{3}\right]\end{array}$ & $\begin{array}{c}115.80 \pm 77.6 \\
99.00[62.00 ; 156.00]\end{array}$ & $\begin{array}{c}117.01 \pm 77.75 \\
99.00[64.00 ; 156.00]\end{array}$ & $\begin{array}{c}107.24 \pm 76.77 \\
84.00[49.00 ; 152.00]\end{array}$ & $p=0.066$ \\
\hline Number of procedures before lead extraction; mean $\pm \mathrm{SD}$ & $1.837 \pm 0.990$ & $1.840 \pm 0.997$ & $1.795 \pm 0.922$ & $p=0.766$ \\
\hline LRIE certain or probable with or without pocket infection; $n(\%)$ & $151(16.132)$ & $108(13.107)$ & $43(38.393)$ & $p<0.001$ \\
\hline Local (pocket) infection (only); $n(\%)$ & $58(6.196)$ & $52(6.311)$ & $6(5.357)$ & $p=0.854$ \\
\hline \multicolumn{5}{|c|}{ TLE efficacy and complications } \\
\hline Major complications (any); $n(\%)$ & $18(1.923)$ & $17(2.063)$ & $1(0.893)$ & $p=0.632$ \\
\hline Hemopericardium; $n(\%)$ & $12(1.282)$ & $11(1.353)$ & $1(0.893)$ & $p=0.954$ \\
\hline Tricuspid severe valve damage during TLE; $n(\%)$ & $6(0.641)$ & $5(0.607)$ & $1(0.893)$ & $p=0.783$ \\
\hline Rescue cardiac surgery; $n(\%)$ & $11(1.175)$ & $10(1.214)$ & $1(0.893)$ & $p=0.864$ \\
\hline Lack of radiological success; $n(\%)$ & $6(0.641)$ & $5(0.607)$ & $1(0.893$ & $p=0.783$ \\
\hline Complete clinical success; $(\%)$ & $916(97.863)$ & $805(97.694)$ & $111(99.107)$ & $p=0.534$ \\
\hline Complete procedural success; $n(\%)$ & 917 (97.761) & $808(98.058)$ & 109 (97.321) & $p=0.872$ \\
\hline
\end{tabular}

Abbreviations: $Q_{1}$ - first quartile, $Q_{3}$ —third quartile, CABG—coronary artery bypass grafting, CHA2DS2-VAsc—Score for Atrial Fibrillation Stroke Risk, CIED—cardiac implantable electronic device, CS—coronary sinus, HV—high voltage, LRIE—lead-related infective endocarditis, LV-left ventricle, TLE—-transvenous lead extraction. 
Table 2. Preoperative TEE findings and preliminary evaluation of their potential influence on long-term survival.

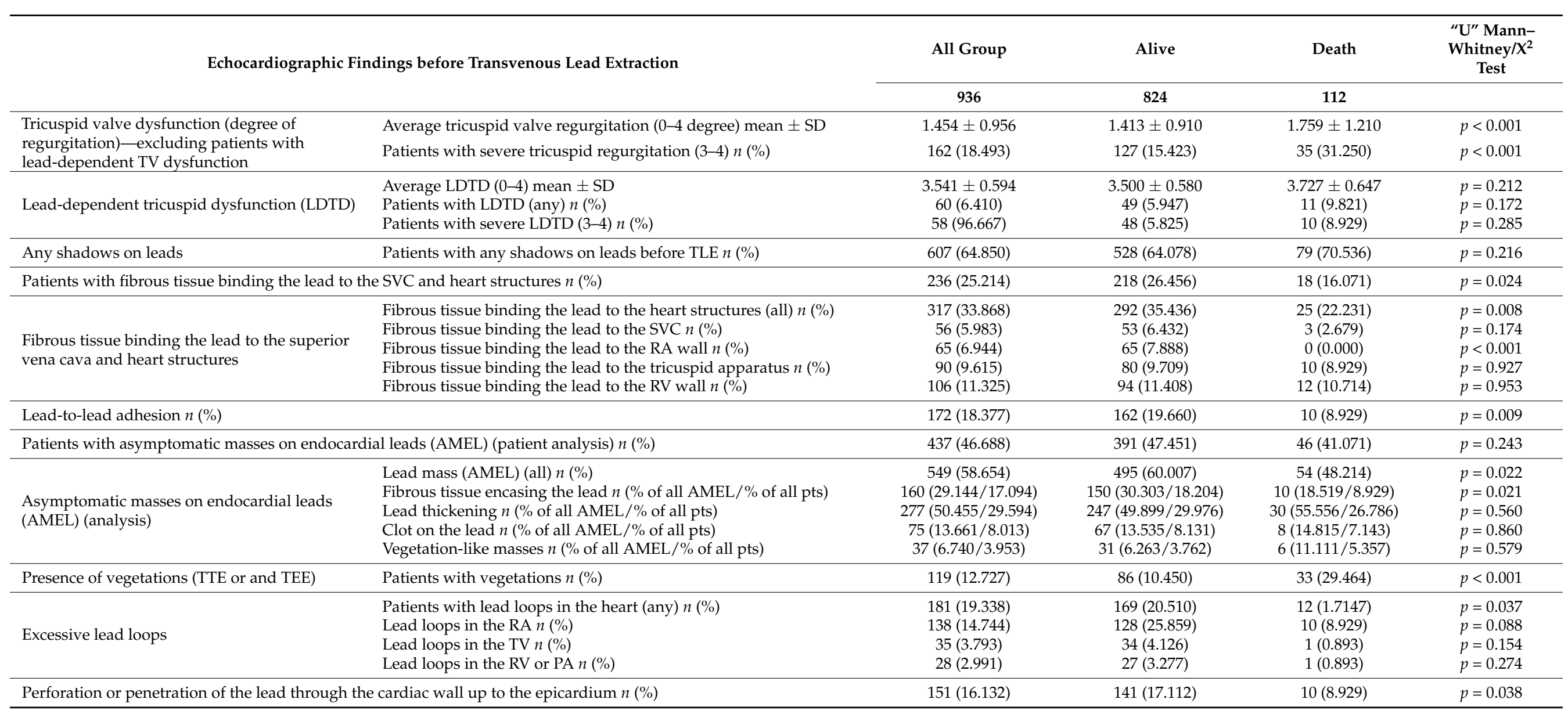

Perforation or penetration of the lead through the cardiac wall up to the epicardium $n(\%)$

Abbreviations: AMEL-asymptomatic masses on endocardial leads, LDTD—lead-d,
TEE—-transesophageal echocardiography, TTE—-transthoracic echocardiography. 


\subsection{Cox's Regression Analysis Results (Model-1; Echocardiographic Data)}

Univariate Cox regression analysis showed a negative relationship between the chances of two-year survival and disease-related parameters only: lead-unrelated TV dysfunction ( $\mathrm{HR}=1.528 ; p<0.001)$ and vegetations $(\mathrm{HR}=3.078 ; p<0.001)$. However, on the other hand, there was a positive relationship between the chances of two-year survival and the following variables (related to implant duration): fibrous tissue encasing the lead $(\mathrm{HR}=0.442 ; p=0.014)$, fibrous tissue binding the lead to the SVC and RA wall $(\mathrm{HR}=0.208$; $p=0.007)$, and lead-to-lead adhesion ( $\mathrm{HR}=0.484 ; p=0.022)$. Additionally, perforation or penetration of the lead through the cardiac wall up to the epicardium $(\mathrm{HR}=0.474$; $p=0.024)$ and excessive lead loops ( $\mathrm{HR}=0.543 ; p=0.033)$ were suggestive of better prognosis (Table 3 ).

Table 3. Prognostic value of preoperative TEE findings after a follow-up of two years in TLE patients, results of univariate and multivariate model-1 Cox regression analysis.

\begin{tabular}{|c|c|c|c|c|c|c|}
\hline & \multicolumn{3}{|c|}{ Univariate Cox Regression } & \multicolumn{3}{|c|}{ Multivariate Cox Regression } \\
\hline & HR & $95 \% \mathrm{CI}$ & $p$ & HR & $95 \% \mathrm{CI}$ & $p$ \\
\hline Lead-dependent TV dysfunction (LDTD) (yes/no) & 1.630 & $0.875-3.037$ & 0.124 & & & \\
\hline TV dysfunction unrelated to lead presence (all) (by one degree) & 1.528 & $1.296-1.801$ & $<0.001$ & 1.481 & $1.261-1.740$ & $<0.001$ \\
\hline Asymptomatic masses on endocardial leads (AMEL) (yes $/$ no) & 0.821 & $0.563-1.196$ & 0.304 & & & \\
\hline Fibrous tissue encasing the lead (yes/no) & 0.442 & $0.231-0.847$ & 0.014 & 0.587 & $0.304-1.132$ & 0.112 \\
\hline Lead thickening (yes/no) & 0.911 & $0.600-1.385$ & 0.664 & & & \\
\hline Clot on the lead (yes/no) & 1.017 & $0.496-2.089$ & 0.962 & & & \\
\hline Vegetation-like masses (yes/no) & 1.495 & $0.657-3.404$ & 0.338 & & & \\
\hline Strong connective tissue scar binding the lead to heart structures (any) (yes/no) & 0.624 & $0.381-1.022$ & 0.061 & & & \\
\hline Fibrous tissue binding the lead to the SVC (yes/no) & 0.414 & $0.131-1.303$ & 0.132 & & & \\
\hline Fibrous tissue binding the lead to the SVC or/and RA wall (yes/no) & 0.208 & $0.066-0.655$ & 0.007 & 0.285 & $0.088-0.919$ & 0.036 \\
\hline Fibrous tissue binding the lead to the tricuspid apparatus (yes/no) & 0.944 & $0.493-1.807$ & 0.861 & & & \\
\hline Fibrous tissue binding the lead to the RV wall (yes/no) & 0.952 & $0.523-1.733$ & 0.872 & & & \\
\hline Fibrous tissue binding the lead to the tricuspid apparatus or/and RV wall (yes/no) & 0.886 & $0.529-1.485$ & 0.646 & & & \\
\hline Lead-to-lead adhesion (yes/no) & 0.484 & $0.260-0.901$ & 0.022 & 0.653 & $0.345-1.235$ & 0.190 \\
\hline $\begin{array}{l}\text { Perforation or penetration of the lead through the cardiac wall up to the epicardium } \\
\text { (yes/no) }\end{array}$ & 0.474 & $0.247-0.907$ & 0.024 & 0.496 & $0.259-0.953$ & 0.035 \\
\hline Excessive lead loops in the heart (yes/no) & 0.543 & $0.310-0.956$ & 0.033 & 0.528 & $0.301-0.928$ & 0.026 \\
\hline Presence of vegetations (yes/no) & 3.078 & $2.042-4.639$ & $<0.001$ & 2.631 & $1.738-3.983$ & $<0.001$ \\
\hline
\end{tabular}

Abbreviations: LDTD—Lead dependent tricuspid valve dysfunction, RV—right ventricle, SVC—superior vena cava, TV—tricuspid valve.

Multivariable Cox regression analysis of TEE variables confirmed the negative relationship between the chances of two-year survival and lead-unrelated TV dysfunction $(\mathrm{HR}=1.481 ; p<0.001)$ and vegetations $(\mathrm{HR}=2.631 ; p<0.001)$, and the positive relationship between fibrous tissue binding the lead to the SVC and/or RA wall ( $\mathrm{HR}=0.285 ; p=0.036$ ), perforation or penetration of the lead through the cardiac wall up to the epicardium $(\mathrm{HR}=0.469 ; p=0.035)$ and excessive lead loops $(\mathrm{HR}=0.528 ; p=0.026)$ (Table 3$)$.

\subsection{Cox's Regression Analysis Results (Model-2; Echocardiographic Data Adjusted with Recognized Clinical Risk Factors)}

Multivariate Cox regression analysis confirmed the negative relationship between the chances of two-year survival and patient's health status parameters such as patient age during TLE (HR $=1.037, p=0.057)$, decreased LVEF (per $\downarrow 10 \%$ p) (HR $=1.168, p=0.051$ ), the presence of chronic renal failure (HR $=1.811 ; p=0.004)$, the lead in the CS before TLE $(\mathrm{HR}=1.610 ; p=0.031)$, long-term anticoagulation $(\mathrm{HR}=1.550, p=0.032)$ and indicationrelated parameters: vegetations $(\mathrm{HR}=2.613 ; p<0.001)$ and lead-related infective endocarditis (LRIE) without vegetations ( $\mathrm{HR}=2.371 ; p<0.017)$. But, on the other hand, the analysis showed several variables predicting significantly better TLE outcomes, i.e., presence of fibrous tissue binding the lead to the SVC and/or RA wall $(\mathrm{HR}=0.270 ; p=0.040)$ and unexpectedly, arterial hypertension $(\mathrm{HR}=0.569 ; p=0.006)$. (Table 4 and Figure 7$)$. 
Table 4. Prognostic value of TEE findings after a follow-up of two years in TLE patients after adjustment of the Cox regression model for common risk factors for poor prognosis, results of univariate and multivariate model-2 Cox regression analysis.

\begin{tabular}{|c|c|c|c|c|c|c|}
\hline & \multicolumn{3}{|c|}{ Univariable Cox Regression } & \multicolumn{3}{|c|}{ Multivariable Cox Regression } \\
\hline & HR & $95 \% \mathrm{CI}$ & $p$ & HR & $95 \% \mathrm{CI}$ & $p$ \\
\hline Lead-dependent TV dysfunction (LDTD) (yes/no) & 1.630 & $0.875-3.037$ & 0.124 & & & \\
\hline TV dysfunction unrelated to lead presence (all) (by one degree) & 1.528 & $1.296-1.801$ & $<0.001$ & 1.128 & $0.937-1.357$ & 0.202 \\
\hline Asymptomatic masses on endocardial leads AMEL (yes/no) & 0.821 & $0.563-1.196$ & 0.304 & & & \\
\hline Fibrous tissue encasing the lead (yes/no) & 0.442 & $0.231-0.847$ & 0.014 & 0.629 & $0.323-1.226$ & 0.174 \\
\hline Lead thickening (yes/no) & 0.911 & $0.600-1.385$ & 0.664 & & & \\
\hline Clot on the lead (yes/no) & 1.017 & $0.496-2.089$ & 0.962 & & & \\
\hline Vegetation-like masses (yes/no) & 1.495 & $0.657-3.404$ & 0.338 & & & \\
\hline Strong connective tissue scar binding the lead to heart structures (any) (yes/no) & 0.624 & $0.381-1.022$ & 0.061 & 1.531 & $0.841-2.787$ & 0.164 \\
\hline Fibrous tissue binding the lead to the SVC (yes/no) & 0.414 & $0.131-1.303$ & 0.132 & & & \\
\hline Fibrous tissue binding the lead to the SVC or/and RA wall (yes/no) & 0.208 & $0.066-0.655$ & 0.007 & 0.270 & $0.077-0.944$ & 0.040 \\
\hline Fibrous tissue binding the lead to the tricuspid apparatus (yes/no) & 0.944 & $0.493-1.807$ & 0.861 & & & \\
\hline Fibrous tissue binding the lead to the RV wall (yes/no) & 0.952 & $0.523-1.733$ & 0.872 & & & \\
\hline $\begin{array}{l}\text { Fibrous tissue binding the lead to the tricuspid apparatus } \\
\text { or/and RV wall (yes/no) }\end{array}$ & 0.886 & $0.529-1.485$ & 0.646 & & & \\
\hline Lead-to-lead adhesion (yes/no) & 0.484 & $0.260-0.901$ & 0.022 & 0.607 & $0.313-1.175$ & 0.138 \\
\hline $\begin{array}{l}\text { Perforation or penetration of the lead through the cardiac wall up to the epicardium } \\
\text { (ves (no) }\end{array}$ & 0.474 & $0.247-0.907$ & 0.024 & 0.562 & $0.289-1.093$ & 0.090 \\
\hline Excessive lead loops in the heart (yes/no) & 0.543 & $0.310-0.956$ & 0.033 & 0.632 & $0.350-1.139$ & 0.127 \\
\hline Presence of vegetations (LRIE with vegetations) (yes/no) & 3.078 & $2.042-4.639$ & $<0.001$ & 2.613 & $1.635-4.176$ & $<0.001$ \\
\hline Female gender (yes/no) & 0.542 & $0.355-0.826$ & 0.004 & 0.812 & $0.511-1.289$ & 0.376 \\
\hline Patient age at first CIED implantation ( $\uparrow$ by 1 year) & 1.040 & $1.023-1.056$ & 0.000 & 0.997 & $0.964-1.031$ & 0.871 \\
\hline Patient age during TLE ( $\uparrow$ by 1 year) & 1.044 & $1.026-1.062$ & 0.000 & 1.037 & $0.999-1.076$ & 0.057 \\
\hline Need for long-term anticoagulation (yes/no) & 2.172 & $1.490-3.165$ & 0.000 & 1.472 & $0.979-2.214$ & 0.063 \\
\hline LVEF ( $\downarrow$ by $10 \%$ p) & 1.420 & $1.261-1.597$ & 0.000 & 1.168 & $0.999-1.360$ & 0.051 \\
\hline NYHA class ( $\uparrow$ by one class) & 2.852 & $2.120-3.838$ & 0.000 & 1.340 & $0.909-1.975$ & 0.139 \\
\hline Chronic renal failure (yes/no) & 3.528 & $2.435-5.111$ & 0.000 & 1.811 & $1.213-2.704$ & 0.004 \\
\hline Diabetes t. 2 (yes/no) & 1.522 & $1.006-2.303$ & 0.047 & 1.209 & $0.780-1.874$ & 0.397 \\
\hline Presence of CS lead before TLE (yes/no) & 2.342 & $1.560-3.516$ & 0.000 & 1.610 & $1.045-2.482$ & 0.031 \\
\hline Presence of ICD lead before TLE (yes/no) & 1.649 & $1.133-2.401$ & 0.009 & 0.930 & $0.573-1.509$ & 0.768 \\
\hline Arterial hypertension (yes/no) & 0.727 & $0.500-1.056$ & 0.094 & 0.569 & $0.381-0.849$ & 0.006 \\
\hline Lead-related infective endocarditis (LRIE) without vegetations (yes/no) & 2.289 & $1.196-4.383$ & 0.012 & 2.371 & $1.166-4.821$ & 0.017 \\
\hline Isolated local pocket infection without general infection (yes/no) & 0.842 & $0.370-1.915$ & 0.681 & & & \\
\hline
\end{tabular}

Abbreviations: RV—right ventricle, SVC—-superior vena cava, TV—tricuspid valve CIED—cardiac implantable electronic device, CScoronary sinus, ICD—implantable cardioverter- defibrillator, LVEF-left ventricular ejection fraction, NYHA class—New York Heart Association class, TLE-transvenous lead extraction.

\section{Kaplan-Mejer probability of survival the time free from death after TLE in 2-years follow-up depending on preoperative TEE diagnosed presence of fibrous tissue bind of lead with vena cava superior} or right atrium wall, $p=0.003$

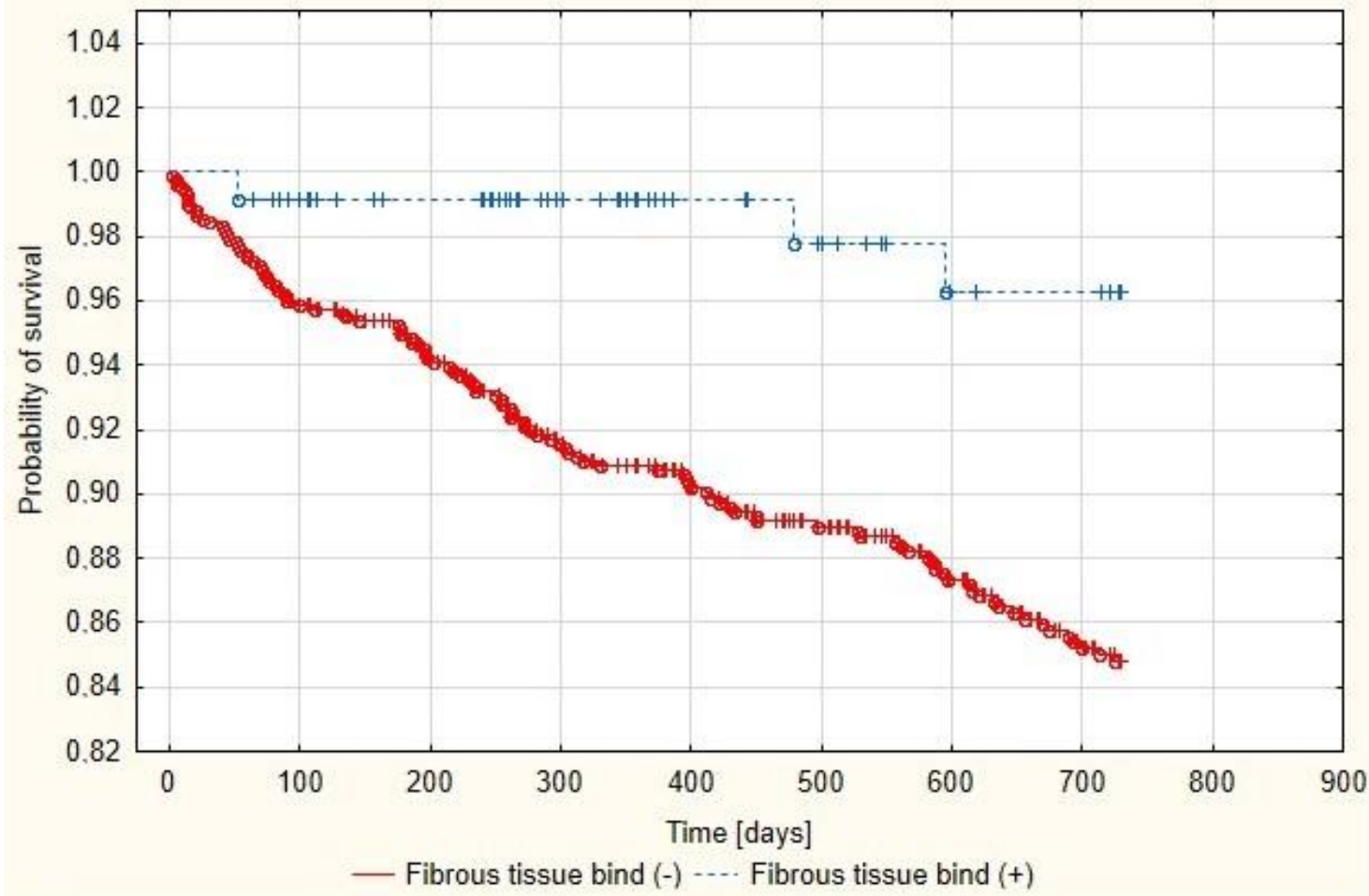

Figure 7. Kaplan-Meier probability of survival after TLE depending on the presence of binding sites between the lead and walls of the superior vena cava or right atrium. 
Results of multivariate model-2 Cox regression analysis are also presented in the Figure S1.

\section{Discussion}

Predicting long-term survival after various procedures, especially those related to the cardiovascular system, is an extremely important element of planning a therapeutic strategy. Transvenous lead extraction has been performed for a relatively short time, and for this reason only few studies have looked at the long-term prognosis of patients after TLE. The available evidence shows that CIED-related infection is the most common prognostic factor for unfavorable outcomes of TLE [5-11,13-15,17-22]. Other factors are mainly those dependent on the patient's general condition i.e., age $[6,13,21,22]$, renal failure $[5-8,10,12,13,16,19-22]$, diabetes [5,16,21], heart failure [7,10,16,22], anemia [8,19], comorbidities [7]. Several studies have demonstrated the significance of procedure-related factors (system upgrade, ICD or CRT device, procedural failure, retained lead fragments, major complications, abandoned leads) $[5,6,11-14,16,21]$ (Table 5).

Echocardiographic phenomena have been very rarely analyzed in terms of their impact on long-term survival after TLE A couple of papers showed only the role of so-called ghosts, i.e., post-removal, tubular, mobile masses following the lead's intracardiac route in the right-sided heart chambers $[15,20]$. The present study set out to investigate the usefulness of preoperative transesophageal echocardiography in the assessment of the long-term survival after TLE. The results are consistent with those observed in earlier studies [5-22] which showed that patient-dependent variables (demographic, related to the underlying disease, comorbidities, systemic infection) were the main risk factors for death at long-term follow-up. CIED-related factors, including the number of leads, left ventricular lead and ICD lead play a significant role, but secondary to the underlying condition $[5,6,11-15,19,21]$. Of the previously identified echocardiographic factors $[7,12,16]$, this study confirms the prognostic value of left ventricular ejection fraction. It should, however be emphasized that the present study was designed to investigate the role of the factors that have not been considered in previous analyses of long-term survival after TLE. Because of the complexity of relationships the preoperative TEE findings and abnormalities were divided into: (1) Non-modifiable factors related to the patient's general condition; (2) non-modifiable factors related to the underlying disease (indication-dependent); (3) factors that have no effect on the procedure course and chances of long-term survival; (4) factors that may increase the complexity of the extraction procedure and the development of complications but which per se do not decrease chances of long-term survival; and (5) abnormalities that can be corrected during the extraction procedure. 
Table 5. Potential risk factors for mortality after TLE during long-time follow-up.

\begin{tabular}{|c|c|c|c|c|c|c|}
\hline \multirow{3}{*}{ Sources } & \multicolumn{6}{|c|}{ Potential Patient- and Co-Morbidity-Related Risk Factors (Normal Type) } \\
\hline & \multicolumn{6}{|c|}{ Potential Infection-Related Risk Factors (Italics) } \\
\hline & \multicolumn{6}{|c|}{ POTENTIAL CIED-, PREVIOUS PROCEDURE- AND TLE-RELATED RISK FACTORS (Capital Letters) } \\
\hline Author & Year & Patients & Most Important Factor & Important Factor & New Observation & No. of Refer. \\
\hline Maytin & 2012 & 985 & Elderly pts, Infections & Diabetes, renal failure & SYSTEM UPGRADE & [5] \\
\hline Deharo & 2012 & $197 \mathrm{Inf}$ & Age, Infection, disease-related factors & Renal failure & Thrombocytopenia, CRT & [6] \\
\hline Habib & 2013 & 415 & Endocarditis, heart failure & Renal failure & Co-morbidities & [7] \\
\hline Deckx & 2014 & $176 \mathrm{Inf}$ & Systemic infection, female sex & Renal failure & Low hemoglobin & [8] \\
\hline Kim & 2014 & $80 \mathrm{IE}$ & Valvular endocarditis $\&$ MRSA infection & & MRSA infection & [9] \\
\hline Tarakji & 2014 & 502 & Systemic infection, concurrent infection & Renal failure & NYHA III/IV & [10] \\
\hline $\mathrm{Fu}$ & 2015 & 652 & Endocarditis & "will be reported" & ABANDONED LEAD(?) & [11] \\
\hline Merchant & 2015 & 508 & LVEF, LEAD NUMBER & Renal failure & PROCEDURAL FAILURE & [12] \\
\hline Gomes & 2016 & 510 & Systemic infection, advanced age & Renal failure & RETAINED LEAD FRAGMENT, MC & [13] \\
\hline Gomes & 2016 & 348 & Endocarditis & & RETAINED LEAD FRAGMENT & [14] \\
\hline Narducci & 2016 & 217 & Endocarditis, systemic infection & & "Ghost" presence & [15] \\
\hline Kutarski & 2016 & 2049 & EF, NYHA class, AF & Renal failure, diabetes & LACK OF CLINICAL SUCCESS, CRT-P & [16] \\
\hline Diemberger & 2018 & 169 & Infection & Presence of vegetations (TEE!!!) & Risk factors for development of CIEDI (Shariff score $\geq 3$ ) & [17] \\
\hline Diemberger & 2019 & 105 CIEDI & Endocarditis & 18F-FDG PET/CT imaging & Endocarditis without pocket infection & [18] \\
\hline Polewczyk & 2016 & $500 \mathrm{IE}$ & Vegetation size, ICD LEAD & Renal failure, $\mathrm{AF}$ & Vegetation remnant, hemoglobin & [19] \\
\hline Diemberger & 2018 & 121 & & Renal failure & $\begin{array}{l}\text { "Ghost" presence } \mathcal{E} \text { closed pocket } \mathcal{E} \text { modified Duke criteria } \\
\text { fulfilled }\end{array}$ & [20] \\
\hline Jacheć & 2017 & 1884 & CIEDI \& pocket infection & $\begin{array}{l}\text { Renal failure, age, diabetes, } \\
\text { infection (any) }\end{array}$ & ICD LEAD & [21] \\
\hline Seifert & 2018 & 537 & Staph aureus & Renal failure, age, & $\begin{array}{l}\text { N-terminal pro B-type natriuretic peptide level } \\
\qquad 3000 \mathrm{pg} / \mathrm{mL}, \mathrm{AF}\end{array}$ & [22] \\
\hline Zucchelli & 2019 & 3555 & $\begin{array}{c}\text { RIATA LEAD OCCLUSION OF SUPERIOR } \\
\text { VENOUS ACCESS UTILITY OF POWERED } \\
\text { ONES }\end{array}$ & $\begin{array}{l}\text { Notice: only for acute outcome } \\
\text { and intrahospital mortality }\end{array}$ & & [34] \\
\hline Segreti & 2019 & 3555 & ABANDONED LEADS & Notice: only for acute outcome & & [35] \\
\hline
\end{tabular}


1. Non-modifiable factors related to the patient's general condition: Tricuspid valve regurgitation (TVR), excluding LDTD, was associated with worse long-term survival in multivariate analysis, but after adjustment for common risk factors for poor prognosis this variable lost its prognostic value. In patients referred for lead extraction TVR is a non-modifiable factor because of right ventricular status.

2. Non-modifiable factors related to the underlying disease (indication-dependent): Vegetations and LRIE have always been (in all previous analyses, including ours) one of the most potent factors decreasing chances of long-term survival [5-22]. Unfortunately, despite the improving standards [2-4] long-term mortality among patients after TLE performed due to LRIE does not improve as desired.

3. Factors that have no effect on the procedure course and chances of long-term survival: AMEL (clots, vegetation-like masses) had no influence on chances of long-term survival in our analysis.

4. Factors that may increase the complexity of the extraction procedure and the development of complications but which, per se, do not decrease chances of long-term survival: fibrous tissue binding the lead to the heart structures, lead-to-lead adhesion. The degree of connective tissue overgrowth in response of the endothelium to longterm irritation by the lead depends on implant duration, stiffness and the number of leads, but first of all on patient age (inverse relationship). This phenomenon has been better documented in papers describing lead removal in children and young patients and in adults with leads implanted in childhood [17]. Surprisingly, the current study found that various forms of connective tissue overgrowth (fibrous tissue binding the lead to the heart structures, lead-to-lead adhesion, lead thickening, scar tissue surrounding the lead) were associated with better long-term survival, although based on previous observations [31,32], connective tissue overgrowth was a predictor of TLE technical difficulty and major complications. This proves that the course of the procedure does not affect prognosis after TLE.

5. Abnormalities that can be corrected during the extraction procedure:

a. Lead-dependent tricuspid dysfunction was not significantly associated with the length of survival. This can be attributed to the fact that most patients with LDTD were referred for the intervention because of the lead propping one of the leaflets open, which was corrected to varying extent during TLE.

b. Excessive lead loops (loop in the right atrium, loop crossing the TV, loop in the right ventricle or pulmonary artery) in univariate and multivariate Cox analysis were significantly associated with better survival odds. The reason was that this abnormality was the indication (main or accompanying) for lead replacement and no patient left our facility with abandoned leads.

c. Perforation, penetration-as was the case of lead loops, perforation/penetration was the main or accompanying indication for lead extraction (most of them were "dry" and caused lead dysfunction or, less frequently, it was an incidental finding or the cause of fluid accumulation in the epicardial space). All perforating/penetrating leads were replaced, thus eliminating their influence on survival and future quality of life. Similar to lead loops, perforations in univariate and multivariate Cox analysis of Model 1 were significantly related to better survival odds.

\section{Limitations}

The current study is a single center observational prospective study. The lead extraction procedure was performed using mechanical tools and not laser sheaths.

\section{Conclusions}

The main factors predicting shorter survival among patients undergoing TLE were those related to the patient (patient age during TLE, male gender, higher NYHA class, 
low LVEF, atrial fibrillation, or chronic renal failure), and those related to the underlying disease, comorbidities and systemic infection.

Non-modifiable factors (patient-dependent and indication/infection-dependent) may have a negative influence on the postoperative course and long-term survival.

The exacerbation of the foreign body reaction resulting in fibrous tissue binding the lead to the vena cava superior or heart structures (especially right atrium wall) seemingly improves chances of longer survival.

Supplementary Materials: The following are available online at https://www.mdpi.com/1660-460 1/18/4/1862/s1, Figure S1: Prognostic value of TEE findings in follow-up of 2 years in TLE patients after adjustment of the Cox regression model for common risk factors for poor prognosis, results of multivariable Cox regression analysis.

Author Contributions: D.N.: Writing—original draft preparation; A.P.: Investigation; W.J.: methodology, statistical study; Ł.T.: Data curation; A.K. (Andrzej Kleinrok): Investigation; A.K. (Andrzej Kutarski): Writing — review and editing. All authors have read and agreed to the published version of the manuscript.

Funding: This research received no external funding.

Institutional Review Board Statement: The study was conducted according to the guidelines of the Declaration of Helsinki, and approved by the institutional Bioethics Committee at Regional Physicians Chamber in Lublin no. 288/2018/KB/VII.

Informed Consent Statement: Informed consent was obtained from all subjects involved in the study.

Data Availability Statement: Readers can access the data supporting the conclusions of the study at www.usuwanieelektrod.pl.

Conflicts of Interest: Authors declare no conflict of interest.

\section{References}

1. Poole, J.E.; Gleva, M.J.; Mela, T.; Chung, M.K.; Uslan, D.Z.; Borge, R.; Gottipaty, V.; Shinn, T.; Dan, D.; Feldman, L.A.; et al. Complication rates associated with pacemaker or implantable cardioverter-defibrillator generator replacements and upgrade procedures: Results from the RE-PLACE registry. Circulation 2010, 122, 1553-1561. [CrossRef] [PubMed]

2. Kusumoto, F.M.; Schoenfeld, M.H.; Wilkoff, B.L.; Berul, C.I.; Birgersdotter-Green, U.M.; Carrillo, R.; Cha, Y.-M.; Clancy, J.; Deharo, J.-C.; Ellenbogen, K.A.; et al. 2017 HRS expert consensus statement on cardiovascular implantable electronic device lead management and extraction. Heart Rhythm. 2017, 14, e503-e551. [CrossRef]

3. Bongiorni, M.G.; Kennergren, C.; Butter, C.; Deharo, J.C.; Kutarski, A.; Rinaldi, C.A.; Romano, S.L.; Maggioni, A.P.; Andarala, M.; Auricchio, A.; et al. The European Lead Extraction ConTRolled (ELECTRa) study: A European Heart Rhythm Association (EHRA) Registry of Transvenous Lead Extraction Outcomes. Eur. Heart J. 2017, 38, 2995-3005. [CrossRef]

4. Blomström-Lundqvist, C.; Traykov, V.; Erba, P.A.; Burri, H.; Nielsen, J.C.; Bongiorni, M.G.; Poole, J.; Boriani, G.; Costa, R.; Deharo, J.C.; et al. European Heart Rhythm Association (EHRA) in-ternational consensus document on how to prevent, diagnose, and treat cardiac implantable electronic device infec-tions-endorsed by the Heart Rhythm Society (HRS), the Asia Pacific Heart Rhythm Society (APHRS), the Latin American Heart Rhythm Society (LAHRS), International Society for Cardiovascular Infectious Diseases (ISCVID), and the European Society of Clinical Microbiology and Infectious Diseases (ESCMID) in collaboration with the European Association for Car-dio-Thoracic Surgery (EACTS). Eur. Heart J. 2020, 57, e1-e31.

5. Maytin, M.; Jones, S.O.; Epstein, L.M. Long-Term Mortality after Transvenous Lead Extraction. Circ. Arrhythmia Electrophysiol. 2012, 5, 252-257. [CrossRef] [PubMed]

6. Deharo, J.-C.; Quatre, A.; Mancini, J.; Khairy, P.; Le Dolley, Y.; Casalta, J.-P.; Peyrouse, E.; Prévôt, S.; Thuny, F.; Collart, F.; et al. Long-term outcomes following infection of cardiac implantable electronic devices: A prospective matched cohort study. Heart 2012, 98, 724-731. [CrossRef]

7. Habib, A.; Le, K.Y.; Baddour, L.M.; Friedman, P.A.; Hayes, D.L.; Lohse, C.M.; Wilson, W.R.; Steckelberg, J.M.; Sohail, M.R.; Mayo Cardio-vascular Infections Study Group. Predictors of mortality in patients with cardiovascular implantable electronic device infec-tions. Am. J. Cardiol. 2013, 111, 874-879. [CrossRef] [PubMed]

8. Deckx, S.; Marynissen, T.; Rega, F.; Ector, J.; Nuyens, D.; Heidbuchel, H.; Willems, R. Predictors of 30-day and 1-year mortality after transvenous lead extraction: A single-centre experience. Europace 2014, 16, 1218-1225. [CrossRef]

9. Kim, D.H.; Tate, J.; Dresen, W.F.; Papa FCJr Bloch, K.C.; Kalams, S.A.; Ellis, C.R.; Baker, M.T.; Lenihan, D.J.; Mendes, L.A. Cardiac im-planted electronic device-related infective endocarditis: Clinical features, management, and outcomes of 80 consecutive pa-tients. Pacing Clin. Electrophysiol. 2014, 37, 978-985. [CrossRef] 
10. Tarakji, K.G.; Wazni, O.M.; Harb, S.; Hsu, A.; Saliba, W.; Wilkoff, B.L. Risk factors for 1-year mortality among patients with cardiac implantable electronic device infection undergoing transvenous lead extraction: The impact of the infection type and the presence of vegetation on survival. Europace 2014, 16, 1490-1495. [CrossRef]

11. Fu, H.-X.; Huang, X.-M.; Zhong, L.; Osborn, M.J.; Asirvatham, S.J.; Espinosa, R.E.; Brady, P.A.; Lee, H.-C.; Greason, K.L.; Baddour, L.M.; et al. Outcomes and Complications of Lead Removal: Can We Establish a Risk Stratification Schema for a Collaborative and Effective Approach? Pacing Clin. Electrophysiol. 2015, 38, 1439-1447. [CrossRef] [PubMed]

12. Merchant, F.M.; Levy, M.R.; Kelli, H.M.; Hoskins, M.H.; Lloyd, M.S.; Delurgio, D.B.; Langberg, J.J.; Leon, A.R.; El-Chami, M.F. Predictors of Long-Term Survival Following Transvenous Extraction of Defibrillator Leads. Pacing Clin. Electrophysiol. 2015, 38, 1297-1303. [CrossRef] [PubMed]

13. Gomes, S.; Cranney, G.; Bennett, M.; Giles, R. Long-Term Outcomes Following Transvenous Lead Extraction. Pacing Clin. Electrophysiol. 2016, 39, 345-351. [CrossRef] [PubMed]

14. Gomes, S.; Cranney, G.; Bennett, M.; Giles, R. Lead Extraction for Treatment of Cardiac Device Infection: A 20-Year Single Centre Experience. Heart Lung Circ. 2017, 26, 240-245. [CrossRef]

15. Narducci, M.L.; Di Monaco, A.; Pelargonio, G.; Leoncini, E.; Boccia, S.; Mollo, R.; Perna, F.; Bencardino, G.; Pennestrí, F.; Scoppettuolo, G.; et al. Presence of 'ghosts' and mortality after transvenous lead extraction. Europace 2016, 19, 432-440. [CrossRef]

16. Kutarski, A.; Czajkowski, M.; Pietura, R.; Obszanski, B.; Polewczyk, A.; Jachec, W.; Polewczyk, M.; Mlynarczyk, K.; Grabowski, M.; Opolski, G. Effectiveness, safety, and long-term outcomes of non-powered mechanical sheaths for transvenous lead extrac-tion. Europace 2018, 20, 1324-1333. [CrossRef]

17. Diemberger, I.; Migliore, F.; Biffi, M.; Cipriani, A.; Bertaglia, E.; Lorenzetti, S.; Massaro, G.; Tanzarella, G.; Boriani, G. The “Subtle” con-nection between development of cardiac implantable electrical device infection and survival after complete system removal: An observational prospective multicenter study. Int. J. Cardiol. 2018, 250, 146-149. [CrossRef]

18. Diemberger, I.; Bonfiglioli, R.; Martignani, C.; Graziosi, M.; Biffi, M.; Lorenzetti, S.; Ziacchi, M.; Nanni, C.; Fanti, S.; Boriani, G. Contribu-tion of PET imaging to mortality risk stratification in candidates to lead extraction for pacemaker or defibrillator infection: A prospective single center study. Eur. J. Nucl. Med. Mol. Imaging 2019, 46, 194-205. [CrossRef] [PubMed]

19. Polewczyk, A.; JacheĆ, W.; Tomaszewski, A.; Brzozowski, W.; Czajkowski, M.; Opolski, G.; Grabowski, M.; Janion, M.; Kutarski, A. Lead-related infective endocarditis: Factors influencing early and long-term survival in patients undergoing transvenous lead extraction. Heart Rhythm. 2017, 14, 43-49. [CrossRef]

20. Diemberger, I.; Biffi, M.; Lorenzetti, S.; Martignani, C.; Raffaelli, E.; Ziacchi, M.; Rapezzi, C.; Pacini, D.; Boriani, G. Predictors of long-term survival free from relapses after extraction of infected CIED. Europace 2018, 20, 1018-1027. [CrossRef]

21. Jacheć, W.; Tomasik, A.; Polewczyk, A.; Kutarski, A. Impact of ICD lead on the system durability, predictors of long-term surviv-al following ICD system extraction. Pacing Clin. Electrophysiol. 2017, 40, 1139-1146. [CrossRef]

22. Seifert, M.; Moeller, V.; Arya, A.; Schau, T.; Hoelschermann, F.; Butter, C. Prognosis associated with redo cardiac resynchronization therapy following complete device and lead extraction due to device-related infection. Europace 2017, 20, 808-815. [CrossRef]

23. Yakish, S.J.; Narula, A.; Foley, R.; Kohut, A.; Kutalek, S.J. Superior Vena Cava Echocardiography as a Screening Tool to Predict Cardiovascular Implantable Electronic Device Lead Fibrosis Cardiovasc. Ultrasound 2015, 23, 27-31.

24. Lo, R.; D'Anca, M.; Cohen, T.; Kerwin, T. Incidence and prognosis of pacemaker lead-associated masses: A study of 1569 transesophageal echocardiograms. J. Invasive Cardiol. 2006, 18, 599-601. [PubMed]

25. Downey, B.C.; Juselius, W.E.; Pandian, N.G.; Mark Estes, I.I.I.N.A.; Link, M.S. Incidence and significance of pacemaker and implant-able cardioverter-defibrillator lead masses discovered during transesophageal echocardiography. Pacing Clin. Electrophysiol. 2011, 34, 679-683. [CrossRef] [PubMed]

26. Strachinaru, M.; Kievit, C.M.; Yap, S.C.; Hirsch, A.; Geleijnse, M.L.; Szili-Torok, T. Multiplane/3D transesophageal echocardiography monitoring to improve the safety and outcome of complex transvenous lead extractions. Echocardiography 2019, 36, 980-986. [CrossRef]

27. Golzio, P.G.; Errigo, D.; Peyracchia, M.; Gallo, E.; Frea, S.; Castagno, D.; Budano, C.; Giustetto, C.; Rinaldi, M. Prevalence and progno-sis of lead masses in patients with cardiac implantable electronic devices without infection. J. Cardiovasc. Med. 2019, 20, 372-378. [CrossRef]

28. Robinson, J.; Wang, W.Y.S.; Kaye, G. Mobile echodensities on intracardiac device leads: Is it always a cause for concern? Pacing Clin. Electrophysiol. 2020, 43, 388-393. [CrossRef] [PubMed]

29. Dundar, C.; Tigen, K.; Tanalp, C.; Izgi, A.; Karaahmet, T.; Cevik, C.; Erkol, A.; Oduncu, V.; Kirma, C. The prevalence of echocardio-graphic accretions on the leads of patients with permanent pacemakers. J. Am. Soc. Echocardiogr. 2011, $24,803-807$. [CrossRef]

30. Bongiorni, M.G.; Burri, H.; Deharo, J.C.; Starck, C.; Kennergren, C.; Saghy, L.; Rao, A.; Tascini, C.; Lever, N.; Kutarski, A.; et al. 2018 EHRA expert consensus statement on lead extraction: Recommendations on definitions, endpoints, research trial design, and data collection requirements for clinical scientific studies and registries: Endorsed by APHRS/HRS/LAHRS. Europace 2018, 20, 1217. [CrossRef]

31. Nowosielecka, D.; Polewczyk, A.; JacheĆ, W.; Tułecki, Ł.; Kleinrok, A.; Kutarski, A. Echocardiographic findings in patients with cardiac implantable electronic devices-analysis of factors predisposing to lead-associated changes. Clin. Physiol. Funct. Imaging 2021, 41, 25-41. [CrossRef] [PubMed] 
32. Nowosielecka, D.; JacheĆ, W.; Polewczyk, A.; Tułecki, Ł.; Tomków, K.; Stefańczyk, P.; Tomaszewski, A.; Brzozowski, W.; Szcześniak-Stańczyk, D.; Kleinrok, A.; et al. Transesophageal Echocardiography as a Monitoring Tool during Transvenous Lead Extraction-Does It Improve Procedure Effectiveness? J. Clin. Med. 2020, 9, 1382. [CrossRef] [PubMed]

33. Nowosielecka, D.; Polewczyk, A.; Jacheć, W.; Tułecki, Ł.; Tomków, K.; Stefańczyk, P.; Kleinrok, A.; Kutarski, A. A new approach to the continuous monitoring of transvenous lead extraction using transesophageal echocardiography-Analysis of 936 proce-dures. Echocardiography 2020, 37, 601-611. [CrossRef] [PubMed]

34. Zucchelli, G.; Di Cori, A.; Segreti, L.; Laroche, C.; Blomstrom-Lundqvist, C.; Kutarski, A.; Regoli, F.; Butter, C.; Defaye, P.; Pasquié, J.L.; et al. Major cardiac and vascular complications after trans-venous lead extraction: Acute outcome and predictive factors from the ESC-EHRA ELECTRa (European Lead Extraction ConTRolled) registry. Europace 2019, 1, 771-780. [CrossRef] [PubMed]

35. Segreti, L.; Rinaldi, C.A.; Claridge, S.; Svendsen, J.H.; Blomstrom-Lundqvist, C.; Auricchio, A.; Butter, C.; Dagres, N.; Deharo, J.-C.; Maggioni, A.P.; et al. Procedural outcomes associated with transvenous lead extraction in patients with abandoned leads: An ESC-EHRA ELECTRa (European Lead Extraction ConTRolled) Registry Sub-Analysis. Europace 2019, 21, 645-654. [CrossRef] 